\title{
Vorrede zur dritten Auflage
}

Seit dem Erscheinen der zweiten Auflage dieses Bandes, I908, haben zwei große Probleme der antiken Kriegsgeschichte ihre Lösung gefunden, die Schlachten bei Salamis und bei Thapsus, und konnten in die Neubearbeitung aufgenommen werden. Platää und Issus durften die Grundzüge der frïheren Darstellung behalten, erfuhren aber auf Grund neuer topographischer Feststellungen Umarbeitung im einzelnen. Die alte Streitfrage von Cannä, ob die Schlacht auf dem rechten oder linken Ufer des Aufidus stattgefunden, ist definitiv entschieden, gleichzeitig aber die quellenmäßige Grundlage des ganzen zweiten punischen Krieges durch eine neue, sehr wirksam begründete Hypothese stark erschüttert worden. Das sind neben mannigfachen Verbesserungen im einzelnen die Punkte, wo sich die neue Auflage von der vorhergehenden unterscheidet.

Gleichzeitig habe ich auch endlich den vierten Band zu Ende geführt und damit das ganze Werk zum Abschluß gebracht.

2I. Juli I920.

Hans Delbrück 